\title{
Genome-wide association analysis and QTL mapping reveal the genetic control of cadmium accumulation in maize leaf
}

Xiongwei Zhao ${ }^{1 \dagger}$, Longxin Luo ${ }^{1 \dagger}$, Yanhua Cao ${ }^{1 \dagger}$, Yajuan Liu', Yuhua $\mathrm{Li}^{1}$, Wenmei Wu', Yuzhou Lan', Yiwei Jiang ${ }^{2}$, Shibin Gao ${ }^{1}$, Zhiming Zhang ${ }^{1}$, Yaou Shen ${ }^{1}$, Guangtang Pan ${ }^{1 *}$ and Haijian Lin ${ }^{1^{*}}$ (ID

\begin{abstract}
Background: Accumulation of cadmium (Cd) in maize (Zea mays L.) poses a significant risk to human health as it is ingested via the food chain. A genome-wide association study (GWAS) was conducted in a population of 269 maize accessions with 43,737 single nucleotide polymorphisms (SNPs) to identify candidate genes and favorable alleles for controlling Cd accumulation in maize.
\end{abstract}

Results: When grown in contaminated soil, accessions varied significantly in leaf $\mathrm{Cd}$ concentration at both the seeding and maturing stages with phenotypic variation and the coefficient of variation all above $48 \%$. The co-localized region between SYN27837 (147,034,650 bp) and SYN36598 (168,551,327 bp) on chromosome 2 was associated with leaf Cd under three soil conditions varying in Cd content in 2015 and 2016. The significant SNP (SYN25051) at position $161,275,547$ could explained $27.1 \%$ of the phenotype variation. Through QTL mapping using the IBMSyn10 double haploid (DH) population, we validated the existence of a major QTL identified by GWAS; qLCd2 could explain the $39.8 \%$ average phenotype variation across the experiments. Expression of GRMZM2G175576 encoding a cadmium/zinc-transporting ATPase underlying the QTL was significantly increased in roots, stems and leaves of B73, a low Cd accumulation line in response to Cd stress.

Conclusions: Our findings provide new insights into the genetic control of $\mathrm{Cd}$ accumulation and could aid rapid development of maize genotypes with low-Cd accumulation by manipulation of the favorable alleles.

Keywords: Maize, Cadmium accumulation association analysis, QTL mapping, Allelic variation, Candidate gene

\section{Background}

Cadmium $(\mathrm{Cd})$ is a heavy metal that is highly toxic to all organisms and is one of the major environmental pollutants. One primary concern is its transfer from crop plants to the human diet. It is concluded that crop plants contribute more than $70 \%$ of cadmium intake in humans [1]. Excessive intake may result in damage from cancers of the prostate, lungs, and testes, kidney tubule damages, emphysema, and bone fractures [2]. Maize (Zea mays L.) is not only a global crop but also a

\footnotetext{
* Correspondence: pangt@sicau.edu.cn; linhj521@gmail.com

${ }^{\dagger}$ Equal contributors

${ }^{1}$ Maize Research Institute, Sichuan Agricultural University, Chengdu 611130,

China

Full list of author information is available at the end of the article
}

primary food source for hundreds of millions of people in developing countries. In Asia, up to $50 \%$ of the ingested $\mathrm{Cd}$ comes from crops and their products, including maize [3]. Because of a serious concern in widespread food safety, research into a better understanding of the mechanisms driving $\mathrm{Cd}$ accumulation in crop plants has become increasingly important.

The pathway of $\mathrm{Cd}$ transport has been elucidated in rice by genetic and genomic approaches [4]. There are three main transport processes most likely to mediate $\mathrm{Cd}$ accumulation in plants. First, roots take up $\mathrm{Cd}$ from soil through the symplastic pathway. In plants, many of the transporters for divalent transition metals have $\mathrm{Cd}$ uptake activity. For example, OsIRT1 controls $\mathrm{Cd}$ absorption and overexpression of 
OsIRT1 increases Cd accumulation [5]. Secondly, Cd accumulation happens through root-to-shoot translocation via xylem loading. The ability of xylemmediated $\mathrm{Cd}$ translocation into shoots has shown to be a major determinant for shoot $\mathrm{Cd}$ accumulation in many plants $[6,7]$. OsHMA3 has been identified as a regulator for xylem $\mathrm{Cd}$ transport in rice by mediating vacuolar sequestration of $\mathrm{Cd}$ in root cells [8]. Third, $\mathrm{Cd}$ is redirected to phloem at nodes and remobilized from leaves to grains. Remobilization of $\mathrm{Cd}$ from leaf blades to grains appears to be regulated by phloem transport [9]. In rice, OsLCT1in leaf blades plays a role in translocation of $\mathrm{Cd}$ from enlarged vascular bundles to diffuse vascular bundles, which connects to the panicle [10]. OsHMA2 is involved in the preferential distribution of $\mathrm{Zn}$ and $\mathrm{Cd}$ at the roots and nodes [11]. All research reports suggest that the various transport systems are involved in $\mathrm{Cd}$ accumulation and differ in their roles in controlling $\mathrm{Cd}$ uptake and translocation.

$\mathrm{Cd}$ accumulation is a complex quantitative trait, controlled by multiple genes. Although the mechanisms of $\mathrm{Cd}$ accumulation are widespread and comprehensive in rice and Arabidopsis thaliana, none of homologous genes that have been involved in the natural genetic variation of $\mathrm{Cd}$ accumulation in rice and $A$. thaliana were cloned in maize. Traditionally, quantitative trait loci (QTLs) have been identified using linkage mapping populations such as recombinant inbred lines (RILs) and double haploid lines (DHs). However, such mapping populations are often generated from a cross between two parental lines. As a result, only a limited amount of natural allelic diversity can be captured in the population, leading to the identified QTLs spanning relatively large genomic regions and making identification of causal genes more difficult. Genome-wide association study (GWAS) utilizes the natural populations for QTL detection though marker-trait association [12, 13]. Integration of linkage mapping and GWAS provides a more powerful tool for identifying and verifying candidate genes underlying complex traits [14]. To date, genetic control of $\mathrm{Cd}$ accumulation is not well understood in crop species, particularly for marker and gene identification using integrated approaches of linkage mapping and GWAS. In this study, we assessed $\mathrm{Cd}$ accumulation in 269 maize genotypes grown at different levels of $\mathrm{Cd}$ contaminated soils in a greenhouse and under field conditions and conducted GWAS for leaf $\mathrm{Cd}$ concentration with the Illumina Infinium maize SNP50K. In addition, a co-located region identified by GWAS was validated through linkage mapping in a ten-generation intermated B73 $\times$ Mo17 (IBMSyn10) DH population with an ultra-high density bin map. Candidate genes and favorable alleles identified in the diversity accessions would assist in further revealing genetic control of $\mathrm{Cd}$ accumulation in maize.

\section{Results \\ Phenotypic variation and heritability}

Two hundred and sixty nine diverse accessions were evaluated for $\mathrm{Cd}$ accumulation of leaves under low-Cd (LSLCd) and middle-Cd (MSLCd) conditions at the seeding stage and under high-Cd condition at the maturing stage (HLCd) in 2015 and 2016, respectively. Analysis of variance (ANOVA) indicated that diverse accessions differed significantly $(P<0.01)$ in $C d$ concentration in leaves, while significant genotype by environment $(\mathrm{Y} \times \mathrm{G})$ interactions were observed $(P<0.01)$ (Table 1). The cultivation environment had a great impact on $\mathrm{Cd}$ accumulation.

The mean HLCd value for individual accessions ranged from 6.76 to $128.4 \mathrm{mg} \cdot \mathrm{kg}^{-1}$ under the high-Cd field condition at the maturing stage. Higher values for HLCd were observed in 2015 with a mean of $47.3 \mathrm{mg} \cdot \mathrm{kg}$ ${ }^{-1}$, compared with $2016\left(\right.$ mean $\left.=21.9 \mathrm{mg} \cdot \mathrm{kg}^{-1}\right)($ Table 1$)$. At the seeding stage, the mean $\mathrm{Cd}$ concentration of leaves (LSLCd) at the low-Cd level ranged from 0.14 to 5.90 with a mean of $1.61 \mathrm{mg} \cdot \mathrm{kg}^{-1}$, whereas the Cd concentration of leaves at the middle-Cd level (MSLCd) varied from 2.79 to $64.3 \mathrm{mg} \cdot \mathrm{kg}^{-1}$, with an average of $22.3 \mathrm{mg} \cdot \mathrm{kg}^{-1}$. The results showed that the $\mathrm{Cd}$ accumulation of leaves in the natural population had a large variation with variation coefficient $(\mathrm{CV})$ over $48 \%$. In addition, the mean value of leaf $\mathrm{Cd}$ concentration in the tropical group was significantly lower than that in the temperate group $(P<0.001)$ in different environments (Fig. 1). Furthermore, the broad-sense heritability $\left(h^{2}\right)$ for $\mathrm{Cd}$ accumulation across all measured environments ranged from $0.62(\mathrm{HLCd})$ to 0.82 (LSLCd), indicating high repeatability over testing environments as well as roles of genetic factors in determining the trait. Overall, the maize plants exhibited significant genetic variations in $\mathrm{Cd}$ concentration when grown at different $\mathrm{Cd}$ levels.

\section{Population structure and linkage disequilibrium (LD)}

The population structure was calculated using 5200 SNPs. Because the log likelihood of data $(\operatorname{LnP}(D))$ from the STRUCTURE output continuously increased with K value, it was not capable of identifying groups. Accordingly, the $\Delta K$ value was calculated for each $K$, suggesting that the 269 genotypes could be assigned into three groups (Fig. 2a). The accessions were divided into tropical, stiff stalk (SS) and non-stiff stalk (NSS) groups. Among them, 50 individuals were assigned to the NSS group, 101 individuals to the SS group, and 118 individuals to the tropical group (Additional file 1). Among them, 92 lines had mixed assignment into these three groups. The average relative kinship between any two 
Table 1 Phenotypic variations for leaf Cd concentration in 269 maize accessions in experiments conducted in 2015 and 2016

\begin{tabular}{|c|c|c|c|c|c|c|c|c|c|}
\hline Year & Trait & No. & $\begin{array}{l}\text { Mean } \pm \mathrm{SD}^{\mathrm{a}} \\
\left(\mathrm{mg} \cdot \mathrm{kg}^{-1}\right)\end{array}$ & $\operatorname{Rang}\left(\mathrm{mg} \cdot \mathrm{kg}^{-1}\right)$ & CV $(\%)^{b}$ & $\mathrm{~F}_{Y}^{\mathrm{C}}$ & $F_{G}^{d}$ & $F_{G \times Y}^{e}$ & $h^{2 f}$ \\
\hline \multirow[t]{3}{*}{2015} & LSLCd & 251 & $1.73 \pm 1.28$ & $0.14-5.90$ & 73.8 & $90.6^{* *}$ & $2.07^{* *}$ & 0.24 & 0.82 \\
\hline & MSLCd & 238 & $25.9 \pm 13.8$ & $3.22-64.3$ & 53.6 & $239.9^{* *}$ & $3.53^{* *}$ & $1.27^{* *}$ & 0.71 \\
\hline & $\mathrm{HLCd}$ & 250 & $47.3 \pm 23.0$ & $16.6-128.4$ & 48.7 & $1178.2^{* *}$ & $9.50^{* *}$ & $1.64^{* *}$ & 0.62 \\
\hline \multirow[t]{3}{*}{2016} & LSLCd & 269 & $1.52 \pm 1.28$ & $0.18-5.36$ & 84.2 & & & & \\
\hline & MSLCd & 249 & $18.6 \pm 9.7$ & $2.79-49.6$ & 52.9 & & & & \\
\hline & $\mathrm{HLCd}$ & 243 & $21.9 \pm 13.9$ & $6.76-83.3$ & 63.6 & & & & \\
\hline
\end{tabular}

The F-test was applied to determine the significance level

** indicates significance at level of 0.01

a SD standard deviation

b variation coefficient $(\mathrm{CV})$

c year

d genotype

e genotype $\times$ year

${ }^{f}$ Broad-sense heritability $\left(h^{2}\right)$

lines was 0.067 . A total of $62.8 \%$ of kinship coefficients were 0 while $27.2 \%$ were between 0 and 0.2 (Fig. 3a), indicating a weak relative kinship in the diverse population.

The extent of LD was estimated with all 43,737 SNPs using TASSEL 5.0. A rapid decline in LD was observed with increasing physical distance on all chromosomes (Fig. 3b), but the decay rate varied over different chromosomes. At a cutoff of $\mathrm{r}^{2}=0.1$, equilibrium was reached within $200-250 \mathrm{~kb}$ on chromosome 1, 250$300 \mathrm{~kb}$ on chromosome 2, and $300-600 \mathrm{~kb}$ on the rest of the chromosomes. The mean LD decay was 350$400 \mathrm{~kb}$ across all chromosomes.

\section{Genome-wide association analysis of $\mathrm{Cd}$ accumulation}

To determine which model was more suitable for association mapping analysis, we used and compared four models for testing each trait. QQ plots showed that the distribution of observed $-\log _{10}(P)$ values from the simple model and Q model departed far from the expected distribution, leading to a high level of false-positive signals. The model controlling $\mathrm{K}$ and $\mathrm{Q}+\mathrm{K}$ had similar effects on reducing the false positives, except that LSLCd16 in the $\mathrm{Q}+\mathrm{K}$ model had lower power than the $\mathrm{K}$ model
(Additional file 2). Thus, we selected the $\mathrm{Q}+\mathrm{K}$ model to identify association signals for LSLCd15, MSLCd15, HLCd15, MSLCd16, HLCd16, and the Q model for LSLCd16.

Across three soil conditions, 63 SNPs located on 5 of the 10 chromosomes were significantly associated with leaf $\mathrm{Cd}$ concentration $\left(P<1.18 \times 10^{-6}\right)$ (Fig. 4, Additional file 3$)$. The association explained approximately $15.9 \%$ of the phenotypic variations. The greatest number of significant SNPs were found with traits collected from the high-Cd field environment (HLCd16, 47 SNPs) at the maturing stage in 2016, followed by the same condition (HLCd15, 30 SNPs) in 2015. However, no significant associations were detected between SNPs and leaf $\mathrm{Cd}$ concentration under the low-Cd condition in 2016 (Additional file 4).

Forty SNPs in a single region on chromosome 2 were highly associated with leaf $\mathrm{Cd}$ concentration (Fig. 4, Additional file 3). Meanwhile, the co-localized peak between SYN27837 (147,034,650 bp) and SYN36598 (168,551,327 bp) explained an average of $17.5 \%$ of the phenotypic variation, based on $R^{2}$ values. SYN25051 (A/G), the most highly significant SNP with $-\log _{10}(P)=13.7$ at position $161,275,547$ on Chr2,
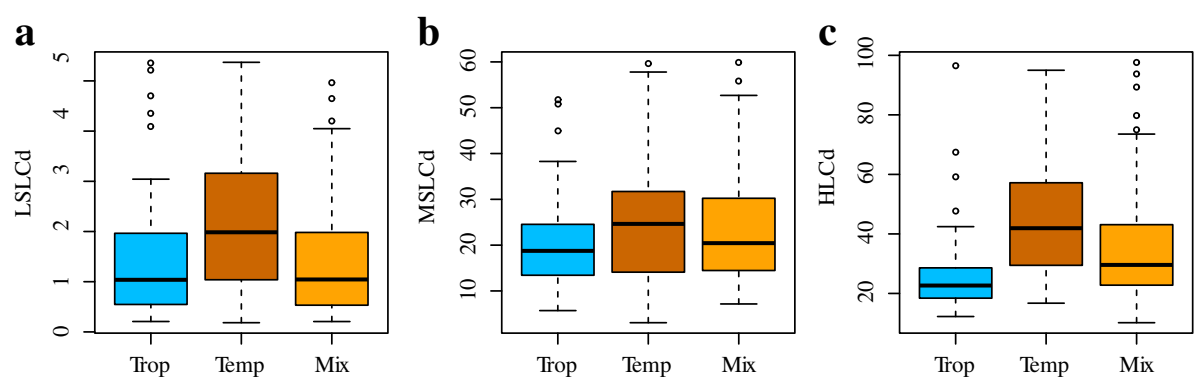

Fig. 1 Distribution of subgroups in maize lines under low-Cd condition (a) and middle-Cd condition (b) at seeding stage and under high-Cd field condition at maturing stage (c). Trop=Tropical group; Temp=Temperature group; Mix = other group with no clear identity 

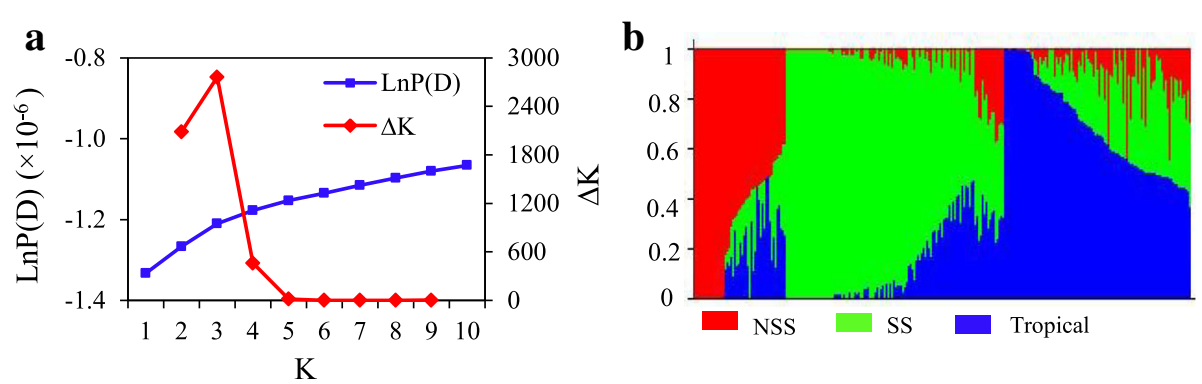

Fig. 2 Analysis of the population structure of 269 maize inbred lines estimated from 5200 SNPs. a Estimated LnP(D) and $\Delta k$ over five repeats of STRUCTURE analysis; $\mathbf{b}$ Population structure of the 269 lines from K=3. SS = Stiff Stalk; NSS = Non-Stiff Stalk

explained $27.1 \%$ of the phenotype variation. In addition, 5 SNPs located on chromosome 5 and 6 SNPs located on chromosome 7 were associated with HLCd16 with $\mathrm{R}^{2}$ values ranging from 12.3 to $17.3 \%$. Nine SNPs on chromosome 1were significantly associated with HLCd16.

\section{QTL mapping for Cd accumulation in IBM Syn10 DH population}

An ultra-high density bin map was used to further confirm the QTL identified from GWAS. The IBMSyn10 DH population was created by crossing the high leaf $\mathrm{Cd}$ line of Mo17 with an $\mathrm{A}$ at Chr2:161,275,547 with a low leaf Cd line of B73 with a G at Chr2:161,275,547 (Additional file 5). The field results showed that the leaf $\mathrm{Cd}$ concentration in $\mathrm{B} 73$ (23.3 $\left.\mathrm{mg} \cdot \mathrm{kg}^{-1}\right)$ was significantly lower than that in Mo17 (64.1 mg. $\mathrm{kg}^{-1}$ ). Leaf $\mathrm{Cd}$ concentration ranged from 9.5 to $114.2 \mathrm{mg} \cdot \mathrm{kg}^{-1}$ in the mapping population, but the phenotypic distribution exhibited a transgressive segregation (Additional file 6). The variation in leaf $\mathrm{Cd}$ concentration suggested that $\mathrm{Cd}$ accumulation was controlled possibly by major-effect QTLs.

Composite interval mapping was performed using the threshold of $L O D \geq 3.84$. Five QTLs for leaf Cd concentration were mapped and located on chromosomes 2, 5 , 7, 8, and 9 (Table 2, Fig. 5). Noteworthy, an overlapped major QTL named qLCd2 (a QTL for leaf Cd concentration on chromosome 2 from GWAS) was identified, spanned a $13.83 \mathrm{Mb}$ region (153.75-167.58 Mb) and explained $41.2 \%$ and $38.4 \%$ of the phenotypic variation in 2015 and 2016, respectively. This major QTL had positive additive effects, which indicated that B73 contributed more to Mo17. Although LOD values of the other 4 QTLs were high, those QTLs explained only $3.4 \%$ to $4.4 \%$ of the phenotypic variation for leaf $\mathrm{Cd}$ accumulation (Table 2). No QTLs in other chromosomal regions were observed by explaining more than $5 \%$ of the variation in leaf $\mathrm{Cd}$ accumulation, suggesting that the $\mathrm{qLCd} 2$ is the major genetic locus controlling natural variation in leaf $\mathrm{Cd}$ accumulation when maize is grown in $\mathrm{Cd}$ contaminated soil.

\section{Prediction of candidate genes}

Based on the results of GWAS and QTL mapping, a major and co-located QTL was associated on chromosome 2, which encompassed a $13.83 \mathrm{Mb}$ region (153.75-167.58 Mb) (Fig. 6a, b). In the comparatively narrow region, GWAS detected a highly significant cluster of 16 SNPs. To determine the traitassociated loci, all significant SNPs located in the target region were clumped at $\mathrm{D}^{\prime}>0.80$. We observed that these 12 SNPs exhibited strong LD and could form two LD blocks (Fig. 6c), which caused an
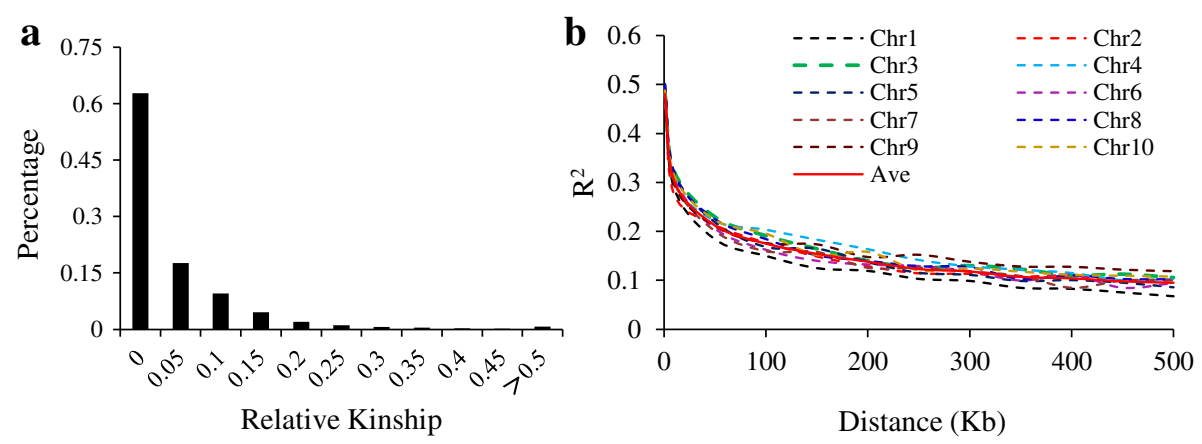

Fig. 3 The distributions of pair-wise kinship and LD decay rate per chromosome. a The distributions of pair-wise kinship between 269 inbred lines; $\mathbf{b} L D$ decay rate per chromosome based on mean $r^{2}$ per $50 \mathrm{~kb}$ region 

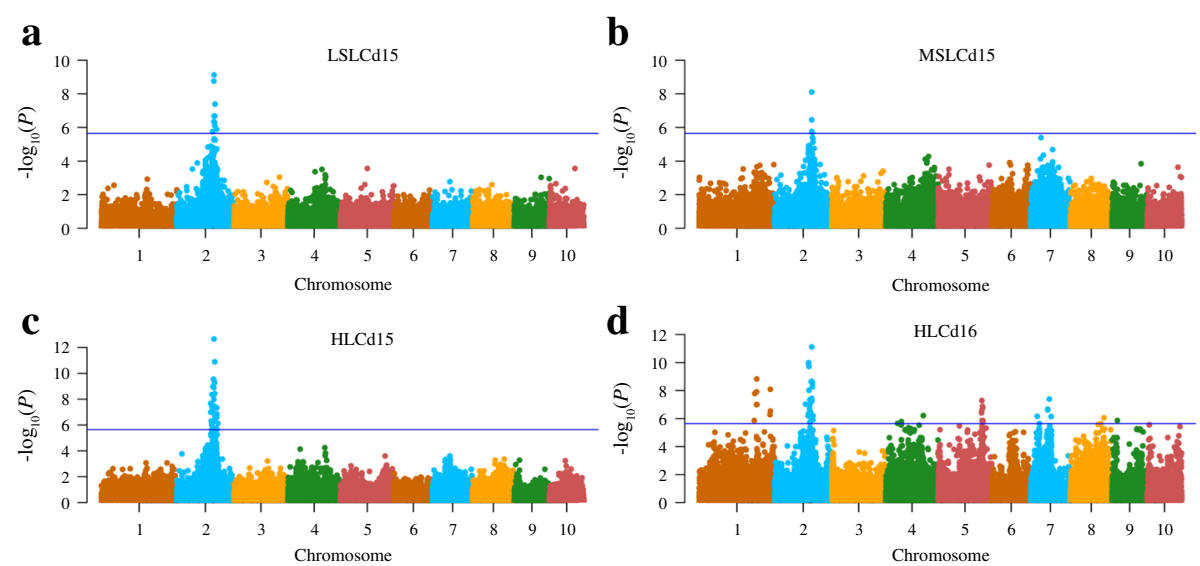

Fig. 4 Manhattan plots of association analysis between leaf $\mathrm{Cd}$ concentration and single-nucleotide polymorphism (SNP) markers in maize. The horizontal dashed blue line represents the significance threshold - $\log _{10}(P)=5.94$. Genome-wide association (GWA) mapping under low-Cd condition (a) and middle-Cd condition (b) at the seeding stage in 2015. GWA mapping of leaf Cd concentration under high-Cd field condition at maturing stage of maize in 2015 (c) and 2016 (d)

overlap with QTL mapping. The first LD block spanned around $3 \mathrm{Mb}$ including 6 SNPs and the second big LD block spanned around $400 \mathrm{~kb}$ including 6 SNPs. Candidate genes were predicted based on the 12 SNPs and their extension regions from $300 \mathrm{~kb}$ upstream to $300 \mathrm{~kb}$ downstream (LD distance of chromosome 2).

Detailed descriptions of 50 candidate genes were summarized in Additional file 7. According to the gene functional annotations in the maize B73 genome (RefGen_v2), 8 causal candidate genes were predicted for 12 loci associated with $\mathrm{Cd}$ accumulation (Table 3 ). Among these genes in the first LD block,
GRMZM2G455491 and GRMZM2G175576, simultaneously encoding a cadmium/zinc-transporting ATPase, were located at $64.18 \mathrm{~kb}$ and $42.64 \mathrm{~kb}$ upstream of the PZE-102118224 and SYN395 loci, respectively. On average, the individuals carrying the major frequency alleles (G/G+G/G) of two SNPs (PZE-102118224, SYN395) had $27.8 \mathrm{mg}$ lower leaf $\mathrm{Cd}$ content than those with minor frequency alleles $(\mathrm{A} / \mathrm{A}+\mathrm{A} / \mathrm{A})$ (Fig. 7a). A putative gene, GRMZM2G124103, encoding a vacuolar ATPase, was found at $72.3 \mathrm{~kb}$ apart from the peak SNP (SYN25051). The individuals carrying the major frequency allele $(\mathrm{G} / \mathrm{G})$ had $29.3 \mathrm{mg} \mathrm{Cd}$ content higher than those with the minor frequency allele (A/A)

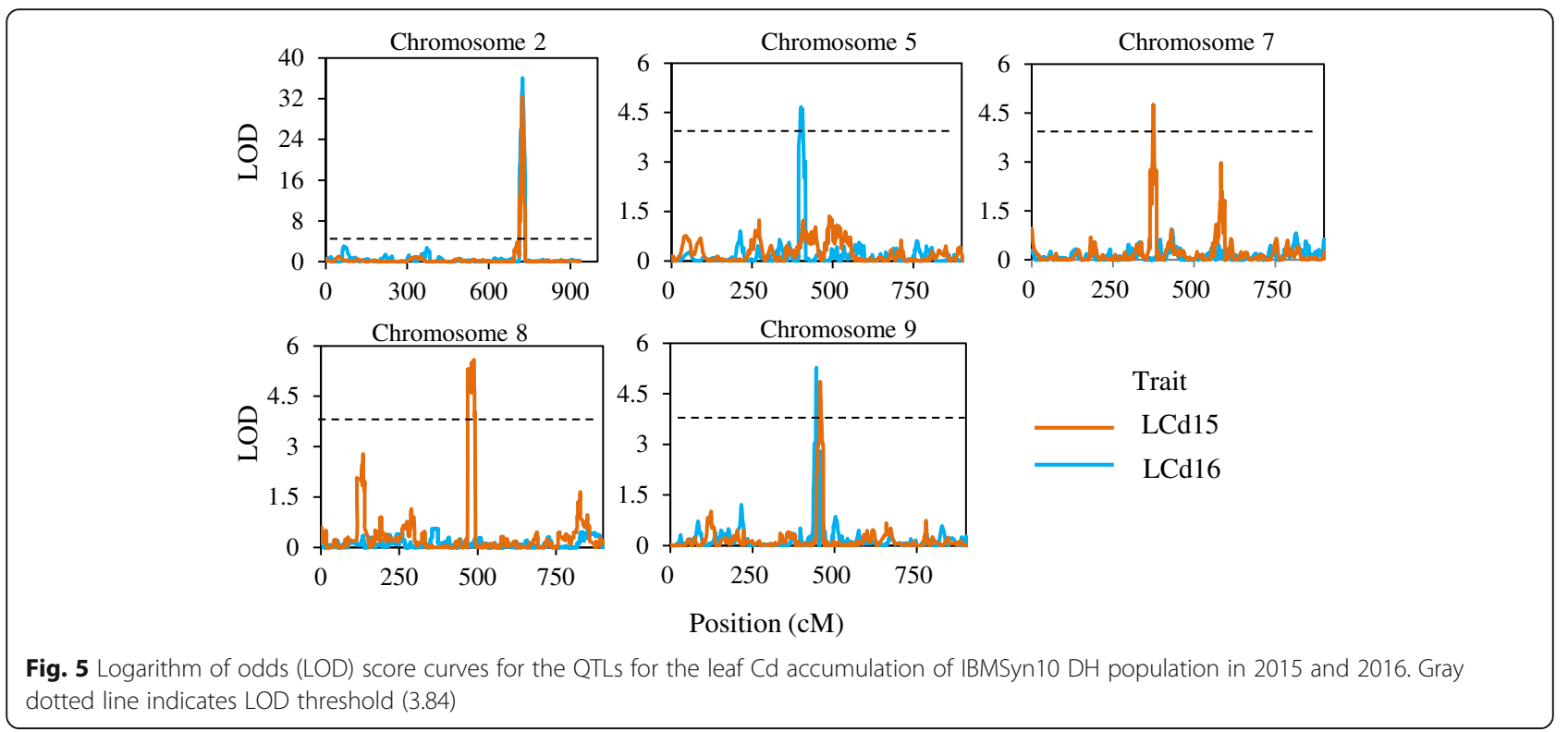


Table 2 QTLs detected for leaf $C d$ accumulation in maize by composite interval mapping

\begin{tabular}{|c|c|c|c|c|c|c|c|c|c|}
\hline No. & Year & QTL & Chr & Pos (cM) & $\operatorname{LOD}^{\mathrm{a}}$ & $R^{2}(\%)$ & A & Support region $(\mathrm{cM})^{\mathrm{b}}$ & Physical distance $(\mathrm{Mb})^{\mathrm{c}}$ \\
\hline \multirow[t]{2}{*}{1} & 2015 & $\mathrm{qLCd} 2$ & 2 & 723.65 & 32.42 & 41.24 & 24.22 & 714.99-728.64 & $154.02-164.30$ \\
\hline & 2016 & & & 723.01 & 36.04 & 38.41 & 13.25 & $712.26-730.91$ & $153.76-167.58$ \\
\hline 2 & 2016 & qLCd5 & 5 & 401.08 & 4.66 & 3.36 & 3.91 & $394.16-415.08$ & $21.30-29.05$ \\
\hline 3 & 2015 & qLCd7 & 7 & 374.39 & 4.76 & 3.75 & 5.97 & $370.29-378.47$ & 113.68-119.73 \\
\hline 4 & 2015 & qLCd8 & 8 & 488.31 & 5.56 & 4.44 & -5.62 & $468.15-491.48$ & $103.10-105.60$ \\
\hline \multirow[t]{2}{*}{5} & 2015 & qLCd9 & 9 & 456.11 & 4.86 & 3.84 & 5.27 & $447.91-462.47$ & $95.85-98.82$ \\
\hline & 2016 & & & 444.46 & 5.27 & 4.29 & 6.92 & $442.45-445.18$ & $93.45-95.08$ \\
\hline
\end{tabular}

Chr chromosome, Pos position of peak with highest logarithm of odds(LOD), $R^{2}$ explained phenotypic variance, $A$ additive effect of B73 allele

a after 1000-permutation tests, threshold values of LOD for Cd concentration of leaves was calculated as 3.84

${ }^{b}$ the position of support regions which was determined by half LOD at the peak in $\mathrm{CM}$

c the physical distance $(\mathrm{Mb})$ of the bin makers corresponding to genetic distance

(Fig. 7b). A ZIP transcription factor, encoded by the putative gene GRMZM2G171370, was targeted by three SNPs, SYN30994, SYN30995, SYN30993. On average, there was $26.4 \mathrm{mg}$ difference in leaf $\mathrm{Cd}$ content between major and minor alleles in three SNPs (Fig. 7d). In the second LD block, SYN33611 and PZE102120786 were located $85.30 \mathrm{~kb}$ upstream and $81.87 \mathrm{~kb}$ downstream of GRMZM2G085939, respectively. The leaf $\mathrm{Cd}$ concentration of individuals with minor frequency alleles $(\mathrm{G} / \mathrm{G}+\mathrm{A} / \mathrm{A})$ at these loci was $28.1 \mathrm{mg}$ higher than those with major frequency alleles $(\mathrm{A} / \mathrm{A}+\mathrm{C} / \mathrm{C})$ (Fig. 7c).

\section{Expression analysis of candidate genes}

Expression profiles of eight candidate genes were examined in maize B73 under non-limiting growth conditions. Using online transcriptome data from maize B73 (MaizeGDB), an expression heatmap was constructed for these candidate genes in different tissues from 8 developmental stages (Fig. 8a). The results showed that the expression patterns of different candidate genes varied greatly in different tissues. GRMZM2G124103 and GRMZM2G047727 showed a relatively high level of expression in all developmental stages compared to the other candidate genes. GRMZM2G175576 in roots had a relatively high level of expression compared to other tissues. On the contrary, GRMZM2G455491 and GRMZM2G386138 exhibited a constitutively low level of expression in different tissues. The expression of 6 candidate genes were examined in leaves, stems and roots of Cd-stressed B73 seedlings by quantitative realtime PCR analyses. As illustrated in Fig. 8b, a dramatic upregulation of the GRMZM2G175576 gene was observed in response to $\mathrm{Cd}$ stress, especially in the stems, exhibiting about a 9.5-fold increase in transcript abundance compared to the control. The relative expression levels of GRMZM2G085939 also significantly increased in the stems and leaves in response to Cd stress. In contrast to the other candidate genes, expression levels of GRMZM2G124103 and GRMZM2G171370 significantly decreased in roots and stems under Cd stress. The expression of GRMZM2G047727 and GRMZM2G085153 had minor response to $\mathrm{Cd}$ exposure. These results suggested that 4 candidate genes possibly played diverse roles in maize development and Cd-stress response and tolerance. Furthermore, possible sub-cellular locations of the candidate genes were predicted using ProtComp 9.0. This prediction suggested that GRMZM2G175576, GRMZM2G124103 and GRMZM2G171370 might be localized in plasma membrane, and vacuolar and nucleus organelles, respectively (Additional file 8 ).

\section{Discussion}

Diverse responses of maize accessions to $\mathrm{Cd}$ treatments provided valuable information about the range and distribution of $\mathrm{Cd}$ concentration in maize and offered new insights into germplasm enhancement for low $\mathrm{Cd}$ accumulation. The mean leaf $\mathrm{Cd}$ concentration in the temperate group was nearly double $\left(P=8 \times 10^{-13}\right)$ that in the tropical group under high-Cd condition (Fig. 1). The relative values of $\mathrm{Cd}$ concentration in the three subpopulations (tropic $<$ Mix $<$ SS $<$ NSS) were consistent with the levels of genetic relatedness of these associations to biotic and abiotic stresses $[15,16]$. The results suggested that the tropical germplasm contained alleles that would provide useful information for exploring genetic variations in reducing $\mathrm{Cd}$ accumulation within SS and NSS. The low-Cd level in the eight lines of 11GP66-1, T32, 98WV9, Wa138, CIMMYT-1, B047, Y8G and CML282 indicated that these lines could be used for developing new maize varieties with low-Cd accumulation.

$\mathrm{Cd}$ accumulation is a complex quantitative trait, controlled by multiple genes. Most previous research on the mechanisms of $\mathrm{Cd}$ accumulation has focused on rice and $A$. thaliana. In rice, a major QTL controlling the translocation of $\mathrm{Cd}$ from roots to shoots at the seedling stage was mapped [17]. Through GWAS, Chao et al. successfully identified a single strong peak of SNPs associated with leaf $\mathrm{Cd}$ accumulation in A. thaliana [18]. In this study, we found 63 loci associated with leaf $\mathrm{Cd}$ 

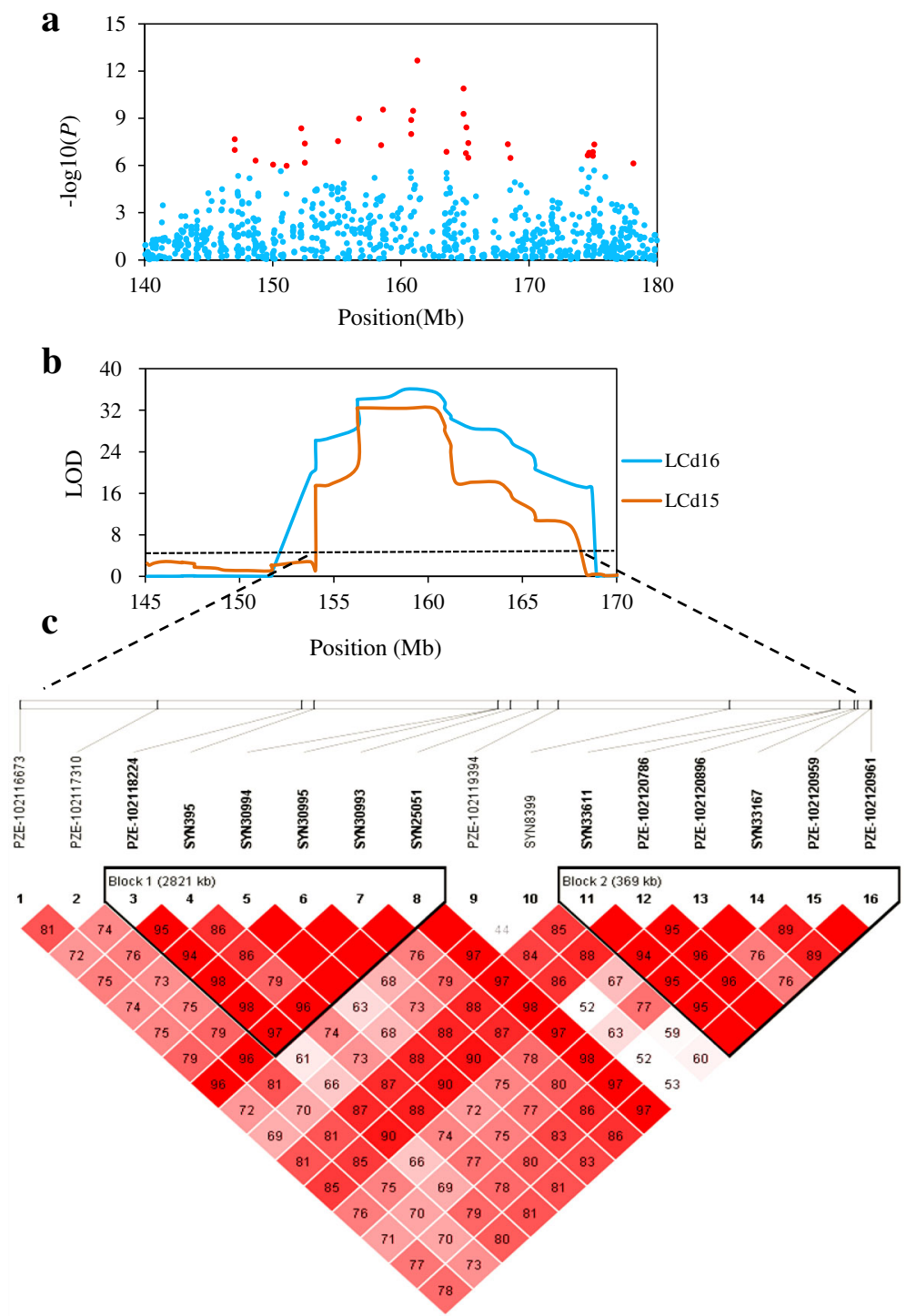

Fig. 6 Genome-wide association analysis detected a significant signal associated with leaf $\mathrm{Cd}$ concentration in maize. a Manhattan plot of association analysis for HLCd15; b The QTL associated with leaf $\mathrm{Cd}$ accumulation in maize at chromosome 2. $\mathbf{c}$ Linkage disequilibrium (LD) between the SNPs in target region (Chr2: 153.75-167.58 Mb) and the magnitude of LD indexed by the D' statistic. Red squares without numbers indicate complete $L D\left(D^{\prime}=1, P<0.01\right)$. $D^{\prime}$ values are shown in the squares for values $<1.0$

accumulation through GWAS. Noteworthy, we observed a single region on chromosome 2 that contained 40 SNPs highly associated with leaf $\mathrm{Cd}$ concentration (Fig. 2). Across all experiments in 2015 and 2016, a major locus identified for $\mathrm{Cd}$ accumulation through GWAS was successfully validated through QTL mapping (Fig. 5). This QTL could explained over 38\% of the phenotypic variation (Table 2), implying that $\mathrm{Cd}$ accumulation in leaves could be controlled by a major QTL. The remaining minor novel QTLs are also of interest but further work is needed to validate these QTLs in controlling $\mathrm{Cd}$ accumulation.
In the comparatively narrow region, GWA detected a highly significant cluster of 16 SNPs on chromosome 2, which extended to the candidate region to a $300 \mathrm{~kb}$ window. According to their putative functions, the candidate genes in support region are primarily involved with DNA binding, catalytic activity, transcription regulator activity and transport. Within the QTL support intervals, the $\mathrm{R}^{2}$ of all markers were over $13.6 \%$, indicating that all these markers had high LD with the causal gene. According to a previous study, LD has been observed for the chromosomes that could be involved in the domestication process 
Table 3 Significant associations and corresponding QTLs detected by genome-wide association study and QTL mapping of leaf Cd concentration at seeding and maturing stage in maize

\begin{tabular}{|c|c|c|c|c|c|c|c|c|c|}
\hline No. & $\begin{array}{l}\text { Possible causative } \\
\text { SNP }\end{array}$ & Allele $^{a}$ & MAF & $\begin{array}{l}\text { Position } \\
\text { (bp) }\end{array}$ & $-\log _{10}(P)$ & $\mathrm{R}^{2}(\%)$ & Candidate gene & Function description & $\begin{array}{l}\text { Distance to } \\
\text { Gene } e^{b}\end{array}$ \\
\hline \multirow[t]{2}{*}{1} & PZE-102118224 & $\underline{A} / G$ & 0.397 & $158,453,594$ & 7.29 & 15.25 & GRMZM2G455491 & Cadmium/zinc-transporting ATPase & $64.18 \mathrm{~kb}$ \\
\hline & & & & & & & GRMZM2G175576 & Cadmium/zinc-transporting ATPase & 42.64 \\
\hline 2 & SYN395 & $\underline{A} / G$ & 0.376 & $158,609,741$ & 9.54 & 20.1 & & & $202.75 \mathrm{~kb}$ \\
\hline 3 & SYN30994 & $\mathrm{A} / \underline{\mathrm{C}}$ & 0.387 & $160,798,026$ & 7.99 & 16.74 & GRMZM2G171370 & ZIP transcription factor & $158.95 \mathrm{~kb}$ \\
\hline 4 & SYN30995 & $\mathrm{A} / \underline{\mathrm{C}}$ & 0.378 & $160,798,113$ & 8.89 & 18.67 & & & $158.86 \mathrm{~kb}$ \\
\hline 5 & SYN30993 & $\mathrm{A} / \underline{\mathrm{C}}$ & 0.352 & $160,957,319$ & 9.48 & 23.03 & & & Intron \\
\hline 6 & SYN25051 & $\underline{A} / \mathrm{G}$ & 0.308 & $161,275,547$ & 12.7 & 27.12 & GRMZM2G124103 & Vacuolar ATPase G subunit & $72.26 \mathrm{~kb}$ \\
\hline 7 & SYN33611 & $\underline{A} / \mathrm{G}$ & 0.386 & $164,889,910$ & 9.28 & 19.52 & GRMZM2G085939 & Calmodulin-binding heat-shock protein & $85.30 \mathrm{~kb}$ \\
\hline 8 & PZE-102120786 & $\mathrm{A} / \underline{\mathrm{C}}$ & 0.329 & $164,893,346$ & 10.9 & 23.1 & & & $81.87 \mathrm{~kb}$ \\
\hline 9 & PZE-102120896 & $\underline{A} / G$ & 0.416 & $165,068,962$ & 6.77 & 14.16 & GRMZM2G386138 & Cupin domain containing protein & Intron \\
\hline 10 & SYN33167 & $\underline{A} / G$ & 0.366 & $165,105,090$ & 8.42 & 17.66 & GRMZM2G047727 & Ubiquitin fusion protein & Intron \\
\hline 11 & PZE-102120959 & $\underline{A} / G$ & 0.414 & $165,259,741$ & 6.49 & 13.56 & GRMZM2G085153 & Nucleic acid binding protein & $2.67 \mathrm{~kb}$ \\
\hline 12 & PZE-102120961 & $\mathrm{A} / \underline{\mathrm{C}}$ & 0.426 & $165,259,881$ & 7.43 & 15.54 & & & $2.53 \mathrm{~kb}$ \\
\hline
\end{tabular}

a The letter under the line is the nucleotide minor frequency

${ }^{b}$ Genes identified within $300 \mathrm{~kb}$ of SNPs detected by the distant of LD decay are indicated

and selection signatures [19]. More importantly, a rapid breakdown of linkage-related LD can be favorable for association testing of candidate genes that are located nearby the mapped QTL and have functional relevance to trait variation [20]. Among these loci on the target region, 12 potential causative loci exhibited the strongest associations and rapid LD (Fig. 6c). Therefore, the LD might cause overlapping effects and/or co-selection by reorganization, mutation, and selection in the evolution process. These chromosome segments can be incorporated into breeding efforts in cultivating a low-Cd accumulation germplasm.

Knowing genes within a QTL region can help understand trait architecture if their function can be related to the associated trait. Once metal ions are absorbed, translocation of $\mathrm{Cd}$ from the roots to the shoots requires loading of $\mathrm{Cd}$ into the xylem from the symplast in the stele. Xylem loading of $\mathrm{Cd}$ in plants requires Heavy Metal ATPases [4]. In this study, GRMZM2G175576, close to the SNP of PZE-102118224, was predicted to encode a heavy metal transporting ATPase, which was homologous to rice clone-gene OsHMA3 [21]. OsHMA3 has been identified as a firewall by sequestrating $\mathrm{Cd}$ into the vacuoles in the roots, keeping the $\mathrm{Cd}$ away from the above-ground tissues [8, 22]. OsHMA3 is localized to the vacuolar membrane, but GRMZM2G175576 is predicted to be localized to the plasma-membrane (Additional file 8). The plant plasma membrane is regarded as the first 'living' structure that is a target for
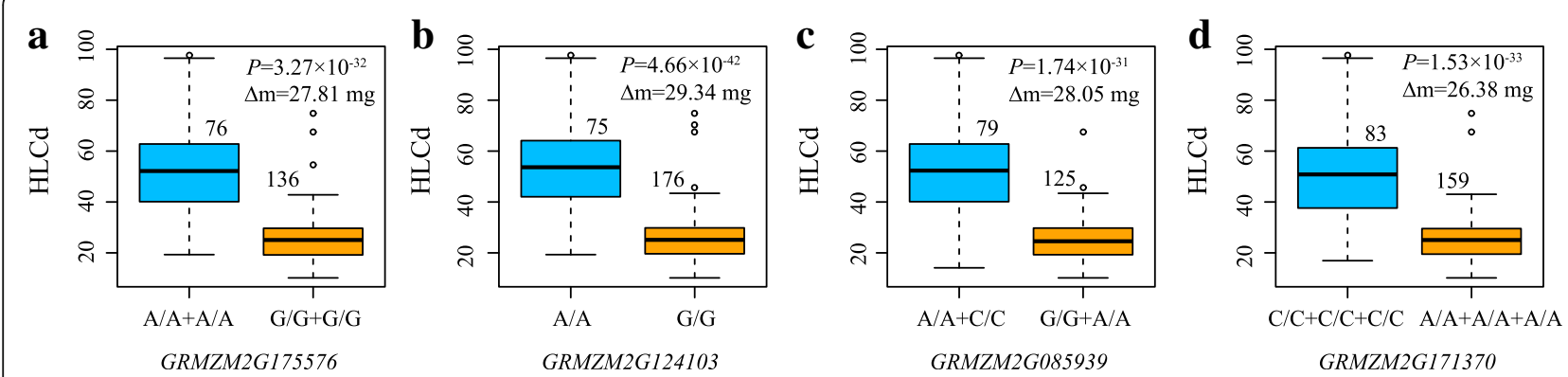

Fig. 7 The boxplot of phenotype analysis between the candidate genes for locus associated with leaf $\mathrm{Cd}$ concentration in maize and phenotypic difference between minor alleles and major alleles. The number above box represents the number of inbred lines homozygous for a determined allelic variant. $\Delta m$, the difference of mean of leaf $\mathrm{Cd}$ concentration between the minor alleles and major alleles at maturing stage over 2 years and 2 replications. a Two combinations of the minor and major between SYN395 and SYN30994 in GRMZM2G175576and GRMZM2G455491region; b The single SYN25051 loci in GRMZM2G124103; c Two combinations of the minor and major between SYN33611 and PZE-102120786 in GRMZM2G085939region; d Three combinations of the minor and major among SYN30994, SYN30995 and SYN30993 in GRMZM2G171370 region 

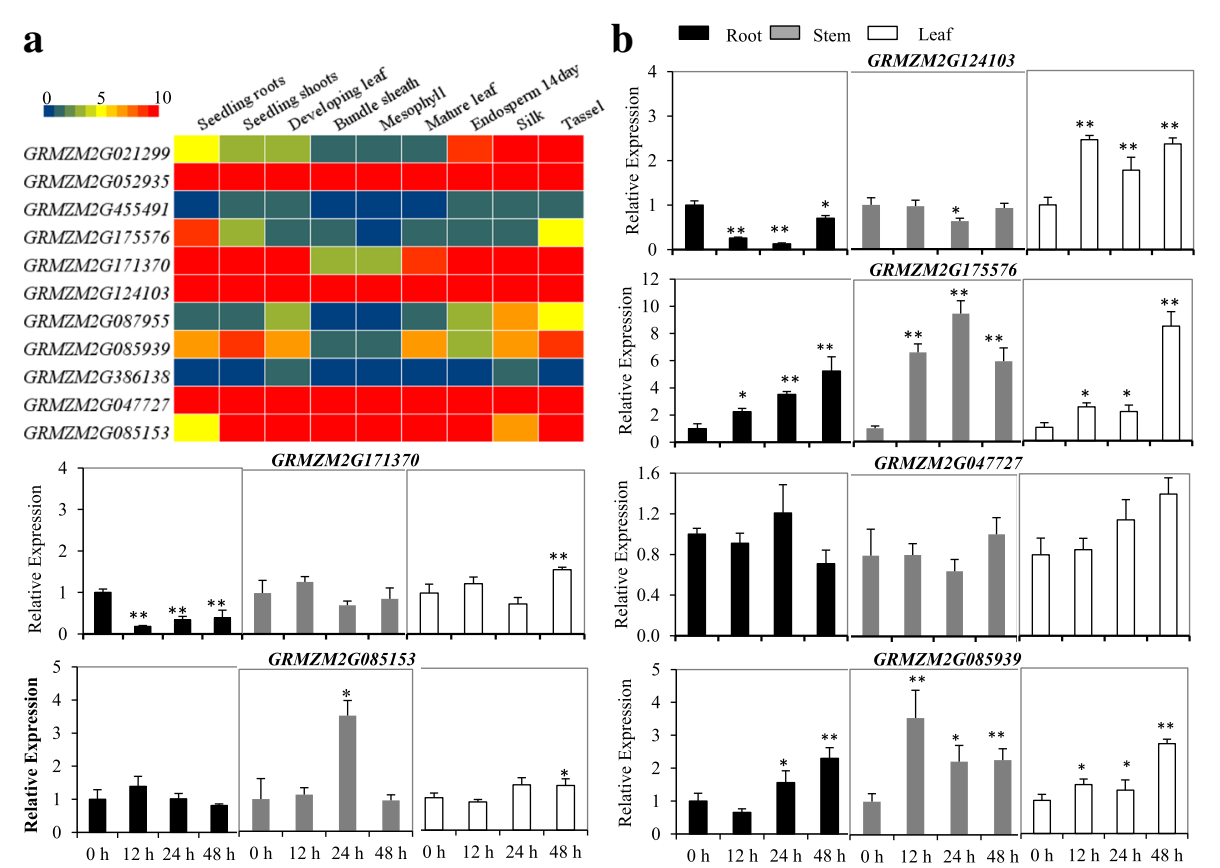

Fig. 8 Expression profiles of putative genes. a A heat map illustrating levels of gene expression of the putative genes in nine different tissues from various developmental stages. $\mathbf{b}$ Relative levels of gene expression in maize B73 roots, stems and leaves for response to $\mathrm{Cd}$ stress; $\mathrm{Cd}$ (200 mg/L) treat for $0 \mathrm{~h}$ (control), 12 h, 24 h, 48 h samples

heavy metal toxicity [23]. These plasma membrane proteins, such as OsHMA2, also mediate Cd transport in plants. Thus a high expression of such proteins might reduce $\mathrm{Cd}$ accumulation in the plant [24]. Exposure of plants to $\mathrm{Cd}$ in nutrient solution for $12 \mathrm{~h}$ caused significant increase in the expression levels of GRMZM2G175576 in roots, stems and leaves of B73 (Fig. 8). All these results indicate that the putative protein GRMZM2G175576, played an important role in controlling $\mathrm{Cd}$ accumulation of maize.

Excess toxic metal may activate defense mechanisms against these toxic metals [25]. Among all defense mechanisms, vacuolar sequestration and plant-mediated bioremediation have received attention [26]. We found that GRMZM2G124103 encoding a vacuolar-type ATPase was located $72.3 \mathrm{~kb}$ apart from the peak SNP (SYN25051), sharing $77 \%$ amino acid sequence identity with the AVMA10. V-ATPase, a type of $\mathrm{H}$ pump, could maintain or adjust the concentration balance of cations on both sides of a membrane, including $\mathrm{Na}^{+}, \mathrm{Ca}^{2+}$, and $\mathrm{Cd}^{2+}[27]$. In a previous report, $L b V H A-c 1$ may confer stress tolerance through tolerance peroxidase and superoxide dismutase activities, protecting membranes from damage and decreasing lipid peroxidation under salt stress [28]. These protein pumps control the movement of ions across the vacuolar membrane, possibly leading to increased $\mathrm{Cd}$ tolerance of the plant. GRMZM2G085939, located downstream of PZE-102120786, encodes a calmodulin binding heat shock protein. Heat shock proteins are expressed in organisms at temperatures above the optimum growth temperatures. HSP17 and HSP70 have been involved in root responses of peruvian tomato (Lycopersicon peruvianum) to $\mathrm{Cu}$ and $\mathrm{Cd}$ [23]. We found that the expression of GRMZM2G085939 significantly increased in roots, stems, and leaves in response to $\mathrm{Cd}$ stress, suggesting that GRMZM2G085939 might be involved in protection and repair of the cellular proteins.

\section{Conclusions}

In briefly, temperate varieties of maize had twice the $\mathrm{Cd}$ concentration as tropical varieties. One region identified by GWAS was co-localized with quantitative trait loci (QTL) and linkage mapping. Three candidate genes, GRMZM2G175576, GRMZM2G124103, and GRMZM $2 G 085939$, underlying the major QTL were proposed, including a gene (GRMZM2G175576) homologous to rice genes (OsHMA3, OsHMA2) that functioned similarly in phenotypic response. Future work will include cloning the genes and illustrating the molecular mechanisms for controlling $\mathrm{Cd}$ accumulation in maize plants. Meanwhile, the identified QTL region could be utilized for the development of $\mathrm{Cd}$ resistant plants.

\section{Methods}

\section{Plant materials}

Two hundred and sixty nine maize accessions for the GWAS were selected from the Southwest China 
breeding program [29], including 17 parents of major expanded hybrids from Southwest China, 160 newly improved inbred lines, 35 representative inbred lines of temperate germplasm (Reid, Lancaster, etc.), and 62 CIMMYT and US imported lines and tropical germplasm. Detailed information of the accessions is listed in Additional file 9. Meanwhile, an IBMSyn10 DH population [30], including 197 doubled haploid lines, was used for QTL analysis.

\section{Plant growing conditions}

Two experiments were conducted for GWAS in maize. The seeding experiment was conducted in pots in a green house at Sichuan Agricultural University (Yaan, Sichuan, China; N $30^{\circ} 08^{\prime}, \mathrm{E} 103^{\circ} 14^{\prime}$ ) during the months of October, 2015 and April, 2016. Eight seeds of each of 269 accessions were initially sown in plastic pots $(22 \mathrm{~cm}$ diameter and $28 \mathrm{~cm}$ deep) containing $14 \mathrm{~kg}$ clayey soil with low $\mathrm{Cd}$ and $\mathrm{pH}$ of 6.3 , and three seedlings were kept after germination. Plants were grown in the greenhouse for $12 \mathrm{~d}$ prior to $\mathrm{Cd}$ treatment. Cd treatments were applied as $\mathrm{Cd}$ solutions with $\mathrm{CdCl}_{2} \cdot 2.5 \mathrm{H}_{2} \mathrm{O}$ at concentrations of 0 (low-Cd level, available $\mathrm{Cd}$ of $3.28 \mathrm{mg} \cdot \mathrm{kg}^{-1}$ in soil) and $0.1 \mathrm{mmol} \cdot \mathrm{kg}^{-1}$ (middle-Cd level, available $\mathrm{Cd} 18.8 \mathrm{mg} \cdot \mathrm{kg}^{-1}$ in soil). The average air temperatures in the greenhouse were $29{ }^{\circ} \mathrm{C} / 21{ }^{\circ} \mathrm{C}$ (day/ night). Irrigation was controlled manually during the experiment to avoid loss of mineral elements and $\mathrm{Cd}$ caused by excessive water. After $15 \mathrm{~d}$ of growth, the third and fourth leaves were harvested for measuring $\mathrm{Cd}$ concentration. The greenhouse experiment was a randomized complete block design with two replications.

A field trial for GWAS was conducted in the summers of 2015 and 2016 in Deyang city, Sichuan province of China $\left(104^{\circ} 06^{\prime} \mathrm{N}, 31^{\circ} 11^{\prime} \mathrm{E}\right)$. Initially, 269 accessions were grown in a greenhouse for 2 weeks under environmental conditions described above. To ensure and obtain uniform plant growth, seedlings were then visually selected and transplanted to the field for phenotypic trait evaluation. Plants were grown in the contaminated soil with $32.5 \mathrm{mg} \cdot \mathrm{kg}^{-1}$ of $\mathrm{Cd}$ (high-Cd level). Each $3 \mathrm{~m}$ row contained 14 plants $0.80 \mathrm{~m}$ apart. The maintenance of plants in the field followed routine practices of maize during the experiment. After seeds matured, five consecutive plants were chosen from the middle of each row, and the middle leaf below the tassel was harvested for measuring $\mathrm{Cd}$ concentration.

For the QTL mapping study, plants of IBMsyn10 DH population were initially grown in a greenhouse for 2 weeks and transplanted to the field. Phenotypic traits were collected from the matured plants of IBMsyn 10 DH population in the summers of 2015 and 2016 in Deyang city, Sichuan province of China $\left(104^{\circ} 06^{\prime} \mathrm{N}, 31^{\circ}\right.$ $\left.11^{\prime} \mathrm{E}\right)$. Plant growing conditions and the procedures of plant sampling were the same as described previously. The field experiment followed a complete randomized plot design with two replications for both GWAS and QTL mapping for both years.

\section{Determination of $\mathrm{Cd}$ concentration and phenotypic data analysis}

All samples were washed thoroughly with tap water to remove soil and dirt, and then were washed with deionized water three times. The leaves were dried and ground until $95 \%$ of the sample could pass through a $1 \mathrm{~mm}$ screen. The powdered sample $(0.5 \mathrm{~g})$ was digested with $20 \mathrm{~mL}$ of $67 \%$ concentrated nitric acid $\left(\mathrm{HNO}_{3}\right)$ and $33 \%$ hydrogen-peroxide $\left(\mathrm{H}_{2} \mathrm{O}_{2}\right)$ on a heating block at $90{ }^{\circ} \mathrm{C}$ for $1 \mathrm{~h}$ and $180{ }^{\circ} \mathrm{C}$ for $5 \mathrm{~h}$. The digested solutions were filtered after dilution with deionized water. Subsequently, the $\mathrm{Cd}$ concentration in the solutions was measured by using the inductively coupled plasma-atomic emission spectrometry (ICP-MS) (Nippon-Jarrell-Ash, Tokyo, Japan).

Analysis of variance (ANOVA) and heritability $\left(h^{2}\right)$ of $\mathrm{Cd}$ concentration in leaves were performed using SPSS statistics 21.0. Broad-sense $(h)$ was estimated as $h^{2}=\sigma_{\mathrm{g}}^{2} /$ $\left(\sigma_{\mathrm{g}}^{2}+\sigma_{\mathrm{ge}}^{2}+\sigma_{\mathrm{e}}^{2}\right)$, where $\sigma_{\mathrm{g}}^{2}, \sigma_{\mathrm{e}}^{2}, \sigma_{\mathrm{ge}}^{2}$ represent TypeIIISS (sums of squares) for genotype $(G)$, environment $(E)$, and interaction variance of $\mathrm{G}$ and $\mathrm{E}$, respectively $[31,32]$.

\section{Population structure, relative kinship and linkage disequilibrium analysis}

In this study, the maizeSNP50K was used to genotype the population as described by Zhang et al. [29]. Through removal of missing rate $>20 \%$, heterozygosity $>20 \%$ and minor allele frequency $(\mathrm{MAF})<0.05$, a total of 43,737 high-quality SNPs were obtained for association analysis.

Population structure (Q matrix) of 269 maize individuals was estimated from a randomly selected set of 5200 high-quality SNPs using STRUCTURE 2.3.4 software with the "admixture model" [33]. The parameter settings for estimating membership coefficients for lines in each subpopulation consisted of a burn-in length of 50,000 followed by 50,000 iterations for each of the clusters $(\mathrm{K})$ from 1 to 10, with each $K$ being run five times. Maximum likelihood and delta $K(\Delta K)$ tests were used to determine the optimum number of subgroups. The relative kinship (K matrix) between lines was calculated using SPAGeD software [34]. All negative values from this software were set to 0 .

Linkage disequilibrium (LD) between pairs of SNPs was estimated by using squared allele frequency correlations between two loci $\left(r^{2}\right)$ in TASSEL 5.0 [35]. Standardized disequilibrium coefficient ( $\left.\mathrm{D}^{\prime}\right)$ and common haplotype patterns were assessed in Haploview version 4.2 [36]. Haplotype blocks were defined with the confidence interval method [37]. 


\section{Genome-wide association analysis}

Marker-trait association analysis was performed by TASSEL 5.0 with the General Linear Model (GLM) and Mixed Linear Model (MLM) procedures [35] to control for population structure (Q) and relative kinship (K). The simple linear model (S), Q (Q matrix) model, K (K matrix) model, and $\mathrm{Q}+\mathrm{K}$ model were applied to assess the suitability of each model for false-positive correction using quantile-quantile (QQ) plots for association analyses. QQ plots and Manhattan plots were generated using the 'qqman' package in R. Associations between SNPs and traits were considered significant only if the $P$-value was lower than threshold $P_{\text {threshold }}=0.05 / \mathrm{N}$, where $\mathrm{N}$ was the total number of SNP markers.

\section{QTL mapping}

Genotypic data previously obtained for the IBMsyn 10 $\mathrm{DH}$ population was used for this QTL mapping [38]. The linkage map included 5955 bins with an average bin size of $344 \mathrm{~kb}$. QTL for leaf Cd accumulation was detected using the composite interval mapping method and Model 6 of the Zmapqtl module of QTL Cartographer 1.17 [39]. The LOD threshold was determined by 1000 permutations and a $10 \mathrm{cM}$ window with scanning intervals at $1 \mathrm{cM}$ interval. Signals were treated as separate QTLs when their peaks were more than $20 \mathrm{cM}$ apart. The support interval of a QTL was defined as the segment of the chromosome in which the LOD at the peak decreased by half [40].

\section{Prediction of candidate genes and expression analysis}

We used the maize B73 reference genome (B73 RefGen_v2, https://www.maizegdb.org/) [41] to identify candidate genes that were either included or close to the significantly associated SNPs. Based on overlapping regions of GWAS and QTL mapping, a region of approximately $300 \mathrm{~kb}$ around the SNP was examined for annotated genes putatively involved in iron transporter and/or regulation by transcription factor [4]. To validate the expression levels of candidate genes obtained by GWAS, expression patterns of candidate genes in different tissues of maize under non-limiting growth conditions were analyzed using online data from MaizeGDB. In addition, the responses of each candidate gene to $\mathrm{Cd}$ stress were analyzed by quantitative real-time PCR (qRT-PCR). Briefly, the 2-week plants of the B73 line were grown in $1 / 2$ Hoagland's nutrient solution amended with $\mathrm{CdCl}_{2} \cdot 2.5 \mathrm{H}_{2} \mathrm{O}\left(200 \mu \mathrm{mol} \cdot \mathrm{L}^{-1}\right)$ for $0 \mathrm{~h}$ (control), 12 , 24, and $48 \mathrm{~h}$. Total RNA was extracted using TRIZOL reagent (Invitrogen, USA) and RNase-free DNase (Takara, Japan) from the roots, stems and leaves. cDNA was synthesized using $1 \mathrm{mg}$ total RNA from each sample by PrimeScript RT Reagent Kit With gDNA Eraser (Perfect Real Time, Takara, Japan). The primer sequences are shown in Additional file 10. Subsequently, qRT-PCR was conducted using the SYBR premix Ex Taq kit (Takara) on an ABI 7500 Real-Time System (Applied Biosystems) and the expression of GADPH was used for normalization. Three replicates were used to calculate expression levels of candidate genes by using the $2^{-\Delta \Delta C T}$ method [42] for each sample. Putative protein subcellular localization was predicted using ProtComp version 9 (http://linux1.softberry.com/berry.phtml) which compared homologous proteins of known localization and pentamer distributions in the LocDB and PotLocDB databases.

\section{Additional files}

\section{Additional file 1: Table S1. The population structure analysis for} accessions using 5200 SNPs by Structure 2.2.3. (XLS 53 kb)

Additional file 2: Figure S1. Quantile-quantile (QQ) plots for leaf $\mathrm{Cd}$ concentration at seeding stage and maturing stage of maize. (PNG $104 \mathrm{~kb}$ )

Additional file 3: Table S2. SNPs significantly associated with leaf $\mathrm{Cd}$ concentration in maize. (XLS $40 \mathrm{~kb}$ )

Additional file 4: Figure S2. Manhattan plots of association analysis for leaf $\mathrm{Cd}$ concentration at seeding stage of maize in 2016. (PNG 64 kb)

Additional file 5: Table S3. Haplotype analysis of polymorphic SNPS contained in the overlapped region (153.75-167.58 Mb) on chromosome 2. (XLS $84 \mathrm{~kb})$

Additional file 6: Figure S3. The frequency distribution of leaf $\mathrm{Cd}$ concentration in maize IBMSyn10 double haploid (DH) population. (PNG $7 \mathrm{~kb})$

Additional file 7: Table S4. Details of the candidate genes in the overlapped region and their putative function. (XLS 30 kb)

Additional file 8: Table S5. The prediction analysis of putative protein sub-cellular localization. (XLS 28 kb)

Additional file 9: Table S6. Pedigree information of 269 maize accessions used in this study. (XLS $45 \mathrm{~kb}$ )

Additional file 10: Table S7. Primers of qRT-PCR assay used for quantifying expression levels of candidate genes within a QTL interval. (XLS $26 \mathrm{~kb})$

\begin{abstract}
Abbreviations
CIM: Composite interval mapping; CIMMYT: International Maize and Wheat Improvement Center; GLM: Linear model; GWAS: Genome-wide association study; HLCd: The $\mathrm{Cd}$ concentration of leaves under the high-Cd condiction at the maturing stage; IBM Syn10 DH population: Intermated B73 $\times$ Mo17 synthetic 10 doubled haploid population; K: Relative kinship; LD: Linkage disequilibrium; LOD: Logarithm of odds; LSLCd: Cd concentration of leaves under low-Cd condition at the seeding stage; MLM: Mixed linear model; MSLCd: The Cd concentration of leaves under the middle-Cd condition at seeding stage; nSS: Non-stiff stalk; Q: Population structure; QQ: Quantilequantile; QTLs: Quantitative trait locus; R $^{2}$ : Percentage of phenotypic variation explained by the identified SNPS; SNP: Single nucleotide polymorphisms; SS: Stiff stalk
\end{abstract}

\section{Acknowledgments}

Authors thank anonymous reviewers for their comments on the manuscript. We would like to thank Thomas Lübberstedt (lowa State University) for providing the IBMSyn10 DH population. 


\section{Availability of data and materials}

All supporting data can be found within the manuscript and its additional files.

\section{Authors' contributions}

$\mathrm{HL}$ and GP conceived and designed the experiments. XZ, LL, YC, YL, YL, WW and $Y L$ performed the experiments. $X Z, Y J$ and $Y C$ supervised manuscript discussion and writing. SG provided pedigree information and genotyping $\mathrm{HL}, \mathrm{ZZ}, \mathrm{YS}, \mathrm{GP}$ conceived the project. All authors discussed the results and commented on the manuscript. All authors read and approved the final manuscript.

\section{Ethics approval and consent to participate}

Not applicable.

\section{Consent for publication}

Not applicable.

\section{Competing interests}

The authors declare that they have no competing interests.

\section{Publisher's Note}

Springer Nature remains neutral with regard to jurisdictional claims in published maps and institutional affiliations.

\section{Author details}

${ }^{1}$ Maize Research Institute, Sichuan Agricultural University, Chengdu 611130, China. ${ }^{2}$ Department of Agronomy, Purdue University, West Lafayette 47906, USA.

Received: 27 April 2017 Accepted: 15 December 2017

Published online: 25 January 2018

\section{References}

1. Wagner GJ. Accumulation of cadmium in crop plants and its consequences to human health. Adv Agron. 1993:51:173-212.

2. Nawrot T, Plusquin M, Hogervorst J, Roels HA, Celis H, Thijs L, Vangronsveld J, Hecke EV, Staessen JA. Environmental exposure to cadmium and risk of cancer: a prospective population-based study. Lancet Oncol. 2006;7(2):119-26.

3. Cheng F, Zhao N, Xu H, Li Y, Zhang W, Zhu Z, Chen M. Cadmium and lead contamination in japonica rice grains and its variation among the different locations in southeast China. Sci Total Environ. 2006;359(1-3):156-66.

4. Uraguchi S, Fujiwara T. Cadmium transport and tolerance in rice: perspectives for reducing grain cadmium accumulation. Rice. 2012:5:5-10.

5. Lee S, Gynheung AN. Over-expression of OsIRT1 leads to increased iron and zinc accumulations in rice. Plant Cell Environ. 2009:32(4):408-16.

6. Murakami M, Nakagawa F, Ae N, Ito M, Arao T. Phytoextraction by rice capable of accumulating $\mathrm{Cd}$ at high levels: reduction of $\mathrm{Cd}$ content of rice grain. Environ Sci Techno. 2009:43(15):5878-83.

7. Uraguchi S, Mori S, Kuramata M, Kawasaki A, Arao T, Ishikawa S. Rootto-shoot $\mathrm{Cd}$ translocation via the xylem is the major process determining shoot and grain cadmium accumulation in rice. J Exp Bot. 2009;60(9):2677-88

8. Ueno D, Yamaji N, Kono I, Huang CF, Ando T, Yano M, Ma JF. Gene limiting cadmium accumulation in rice. Proc Natl Acad Sci U S A. 2010;107(38): 16500-5.

9. Matthew SR, Gang L, Robert JR. The timing of grain Cd accumulation in rice plants: the relative importance of remobilisation within the plant and root Cd uptake post-flowering. Plant Soil. 2011;347(1-2):105-14.

10. Uraguchi S, Kamiya T, Sakamoto T, Kasai K, Sato Y, Nagamura Y, Yoshida A, Kyozuka J, Ishikawa S, Fujiwara T. Low-affinity cation transporter (OsLCT1) regulates cadmium transport into rice grains. Proc Natl Acad Sci U S A. 2011;108(52):20959-64

11. Yamaji N, Xia J, Mitani-Ueno N, Yokosho K, Ma J. Preferential delivery of zinc to developing tissues in rice is mediated by P-type heavy metal ATPase OsHMA2. Plant Physiol. 2013;162(2):927-39.

12. Ueda Y, Frimpong F, Qi Y, Matthus E, Wu L, Höller S, Kraska T, Frei M. Genetic dissection of ozone tolerance in rice (Oryza sativa L.) by a genomewide association study. J Exp Bot. 2015;66(1):293-306.
13. Zhang $X$, Warburton ML, Setter T, Liu H, Xue Y, Yang N, Yan J, Xiao Y. Genome-wide association studies of drought-related metabolic changes in maize using an enlarged SNP panel. Theor Appl Genet. 2016;129(8):1449-63.

14. Nicod J, Davies RW, Cai N, Hassett C, Goodstadt L, Cosgrove C, Yee BK, Lionikaite V, McIntyre RE, Remme CA. Genome-wide association of multiple complex traits in outbred mice by ultra-low-coverage sequencing. Nat Genet. 2016;48(8):912-8

15. Zila CT, Ogut F, Romay MC, Gardner CA, Buckler ES, Holland JB. Genome-wide association study of Fusarium ear rot disease in the USA maize inbred line collection. BMC Plant Biol. 2014;14(1):372.

16. Yang X, Gao S, Xu S, Zhang Z, Prasanna BM, Li L, Li J, Yan J. Characterization of a global germplasm collection and its potential utilization for analysis of complex quantitative traits in maize. Mol Breed. 2011;28(4):511-26.

17. Ueno D, Kono I, Yokosho K, Ando T, Yano M, Ma J. A major quantitative trait locus controlling cadmium translocation in rice (Oryza Sativa). New Phytol. 2009:182(3):644-53.

18. Chao DY, Silva A, Baxter I, Huang YS, Nordborg M, Danku J, Lahner B, Yakubova E, Salt DE. Genome-wide association studies identify heavy metal ATPase 3 as the primary determinant of natural variation in leaf cadmium in Arabidopsis Thaliana. PLoS Genet. 2012:8(9):e1002923.

19. Li Y, Zhao S, Ma J, Li D, Yan L, Li J, Qi X, Guo X, Zhang L, He W. Molecular footprints of domestication and improvement in soybean revealed by whole genome re-sequencing. BMC Genomics. 2013;14(1):579.

20. Zhu C, Gore M, Buckler ES, Yu J. Status and prospects of association mapping in plants. Plant Genome. 2008;1(1):5-20.

21. Jin T, Chen J, Zhu L, Zhao Y, Guo J, Huang Y. Comparative mapping combined with homology-based cloning of the rice genome reveals candidate genes for grain zinc and iron concentration in maize. BMC Genet. 2015;16(1):17.

22. Miyadate H, Adachi S, Hiraizumi A, Tezuka K, Nakazawa N, Kawamoto T, Katou K, Kodama I, Sakurai K, Takahashi H. OsHMA3, a P1B-type of ATPase affects root-to-shoot cadmium translocation in rice by mediating efflux into vacuoles. New Phytol. 2011;189(1):190-9.

23. Hall J. Cellular mechanisms for heavy metal detoxification and tolerance. J Exp Bot. 2002:53(366):1-11.

24. Takahashi R, Ishimaru Y, Shimo H, Ogo Y, Senoura T, Nishizawa NK, Nakanishi $\mathrm{H}$. The OsHMA2 transporter is involved in root-to-shoot translocation of Zn and Cd in rice. Plant Cell Environ. 2012;35(11):1948-57.

25. Sytar O, Kumar A, Latowski D, Kuczynska P, Strzałka K, Prasad M. Heavy metal-induced oxidative damage, defense reactions, and detoxification mechanisms in plants. Acta Physiol Plant. 2013;35(4):985-99.

26. Sharma SS, Dietz KJ, Mimura T. Vacuolar compartmentalization as indispensable component of heavy metal detoxification in plants. Plant Cell Environ. 2016;39:1112-26.

27. Dietz K-J, Tavakoli N, Kluge C, Mimura T, Sharma S, Harris G, Chardonnens A, Golldack D. Significance of the V-type ATPase for the adaptation to stressful growth conditions and its regulation on the molecular and biochemical level. J Exp Bot. 2001;52(363):1969-80.

28. Xu C, Zheng L, Gao C, Wang C, Liu G, Jiang J, Wang Y. Ovexpression of a vacuolar $\mathrm{H}^{+}$-ATPase $\mathrm{C}$ subunit gene mediates physiological changes leading to enhanced salt tolerance in transgenic tobacco. Plant Mol Biol Rep. 2011; 29(2):424-30.

29. Zhang X, Zhang H, Li L, Ren Z, Liu D, Wu L, Liu H, Jennifer J, Li B, Pan G, et al. Characterizing the population structure and genetic diversity of maize breeding germplasm in Southwest China using genome-wide SNP markers. BMC Genomics. 2016;17(1):697.

30. Hussain T, Tausend P, Graham G, Ho J. Registration of IBM2 SYN10 doubled haploid mapping population of maize. J Plant Reg. 2007;1:81.

31. Holland JB, Nyquist WE, Cervantes-Martínez CT. Estimating and interpreting heritability for plant breeding: an update. Plant Breed Rev. 2003;22:9-112.

32. Samayoa LF, Malvar RA, Olukolu BA, Holland JB, Butrón A. Genome-wide association study reveals a set of genes associated with resistance to the Mediterranean corn borer (Sesamia nonagrioides L.) in a maize diversity panel. BMC Plant Biol. 2015;15(1):35

33. Falush D, Stephens M, Pritchard JK. Inference of population structure using multilocus genotype data: linked loci and correlated allele frequencies. Genetics. 2003:164(4):1567-87.

34. Hardy OJ, Xavier V. SPAGeDi: a versatile computer program to analyse spatial genetic structure at the individual or population levels. Mol Ecol Notes. 2002;2(2):618-20. 
35. Bradbury PJ, Zhang Z, Kroon DE, Casstevens TM, Ramdoss Y, Buckler ES. TASSEL: software for association mapping of complex traits in diverse samples. Bioinformatics. 2007;23(19):2633-5.

36. Barrett JC, Fry B, Maller J, Daly MJ. Haploview: analysis and visualization of LD and haplotype maps. Bioinformatics. 2005;21(2):263-5.

37. Gabriel SB, Schaffner SF, Nguyen H, Moore JM, Roy J, Blumenstiel B, Higgins J, DeFelice M, Lochner A, Faggart M. The structure of haplotype blocks in the human genome. Science. 2002;296(5576):2225-9.

38. Liu H, Niu Y, Gonzalez-Portilla PJ, Zhou H, Wang L, Zuo T, Qin C, Tai S, Jansen $C$, Shen $Y$. An ultra-high-density map as a community resource for discerning the genetic basis of quantitative traits in maize. BMC Genomics. 2015;16(1):1078

39. Basten CJ, Weir BS, Zeng ZB. QTL Cartographer, version 1.17, vol. 189. Raleigh: Department of Statistics, North Carolina State University; 2004.

40. Ruta N, Liedgens M, Fracheboud Y, Stamp P, Hund A. QTLs for the elongation of axile and lateral roots of maize in response to low water potential. Theor Appl Genet. 2010;120(3):621-31.

41. Schnable PS, Ware D, Fulton RS, Stein JC, Wei F, Pasternak S, Liang C, Zhang J, Fulton L, Graves TA. The B73 maize genome: complexity, diversity, and dynamics. Science. 2009;326(5956):1112-5.

42. Schefe JH, Lehmann KE, Buschmann IR, Unger T, Funke-Kaiser $H$. Quantitative real-time RT-PCR data analysis: current concepts and the novel "gene expression's CT difference" formula. J Mol Med. 2006;84(11):901-10.

\section{Submit your next manuscript to BioMed Central and we will help you at every step:}

- We accept pre-submission inquiries

- Our selector tool helps you to find the most relevant journal

- We provide round the clock customer support

- Convenient online submission

- Thorough peer review

- Inclusion in PubMed and all major indexing services

- Maximum visibility for your research

Submit your manuscript at www.biomedcentral.com/submit

) Biomed Central 